Review Article

\title{
PHOTODEGRADATION OF 1, 4-DIHYDROPYRIDINE ANTIHYPERTENSIVE DRUGS: AN UPDATED REVIEW
}

\author{
MICHELE DE LUCA, GIUSEPPINA IOELE, CLAUDIA SPATARI, GAETANO RAGNO*
}

Department of Pharmacy, Health and Nutritional Sciences, University of Calabria, 87036 Rende, Italy

Email: gaetano.ragno@unical.it

Received: 14 Sep 2017 Revised and Accepted: 07 Dec 2017

\begin{abstract}
1, 4-dihydropyridine calcium channels blockers (DHPs) are the most commonly used antihypertensive drugs. Unfortunately, these compounds have a significant degradability to light. The oxidation to the pyridine derivative represents the first, and in many cases the only, step of the degradation mechanism. The photodegradation process causes the complete loss of pharmacological activity and may trigger the formation of single and superoxide oxygen species, potentially responsible for phototoxic reactions. Several analytical techniques have been proposed for DHP determination in the presence of their photoproducts. Nowadays, DHPs are all marketed in solid formulations, especially tablets, because photodegradation is particularly fast in solution. Various approaches aimed to protect molecular integrity and therapeutic activity of these drugs from the effects of light are currently studied. This review covers the studies over the last years about photodegradation of the DHPs and the approaches to obtain photostable formulations of these drugs.
\end{abstract}

Keywords: 1, 4-Dihydropyridine drugs, Photodegradation, Phototoxicity, Photostabilization, Stressing test

(c) 2018 The Authors. Published by Innovare Academic Sciences Pvt Ltd. This is an open access article under the CC BY license (http://creativecommons.org/licenses/by/4.0/) DOI: http://dx.doi.org/10.22159/ijpps.2018v10i1.22562

\section{INTRODUCTION}

Calcium channel blockers are drugs known and used in clinical practice for many years. The first drug of this class was verapamil, introduced in therapy in the $60 \mathrm{~s}$ as a selective coronary vasodilator and become in 80-90 y the best-selling antihypertensive agent. Another important step was reached in 1969 with the discovery of nifedipine, the lead of the 1,4-dihydropyridine drugs (DHPs), approved for use in the United States in 1981. Nowadays, the calcium channel blockers are the most prescribed drugs in hypertensive patients [1]. Chemically, they are classified into two main categories, DHP derivatives and non-DHP derivatives, comprising verapamil and diltiazem congeners [2].

These drugs act on voltage-operated channels (VOC) by binding to the channel during the inactivated state, thereby prolonging the duration of this state and, therefore, preventing the entry of calcium into the cell [3]. The consequence is the impediment to the smooth muscles to contract, producing a final relaxation of muscle peripheral resistance and hence hypotension [4]. The effects are expressed on smooth and cardiac muscle and even beyond the blood-brain barrier. In fact, some DHPs work better on certain types of vessels, for example on the coronary arteries or the cerebral vessels [5]. The striated muscles are free from these effects because the mechanism is a function of the calcium already present within the cells.

Several congeners have been synthesized and marketed after nifedipine, which have improved and expanded the therapeutic effects and at the same time sought to limit side effects and prolong the half-life. Currently, calcium antagonists used as antihypertensive agents are almost exclusively DHP compounds, while non-DHP drugs are mainly used as antiarrhythmics [5-7].

DHPs can be classified in three generations:

- A first-generation comprising above all nifedipine and nicardipine;

- A second-generation including felodipine, nimodipine, nisoldipine, nitrendipine, isradipine;

- A third-generation comprising amlodipine, barnidipine, lacidipine, lercanidipine, manidipine.

In particular, the DHPs belonging to the third-generation are characterized by a longer half-life, due to a higher lipophilicity and receptor affinity. At the same time, they present reduction of side effects, as headache, excessive hypotension, edema and tachycardia.

Studies on photodegradation of drugs, and in particular DHP antihypertensive, have begun for many years but the number of publications on this topic has increased over time, demonstrating a great deal of interest by a good number of researchers. This review focuses on the results published over the last twenty years. In some cases, the reported references are of previous years but have been of great importance to the subject or are the only ones published for a particular drug.

Table 1 lists the main DHPs used in therapy.

Table 1: Chemical structures of dihydropyridine drugs

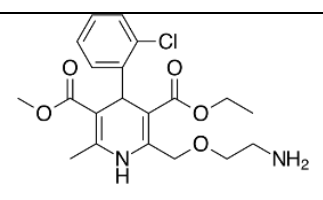

Amlodipine

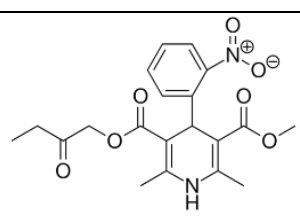

Aranidipine

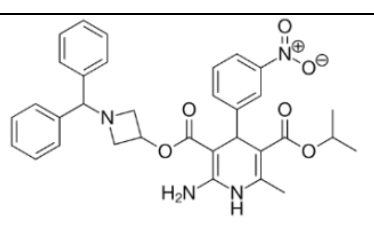

Azelnidipine

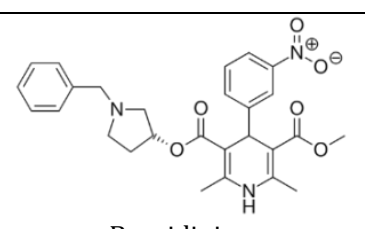

Barnidipine 


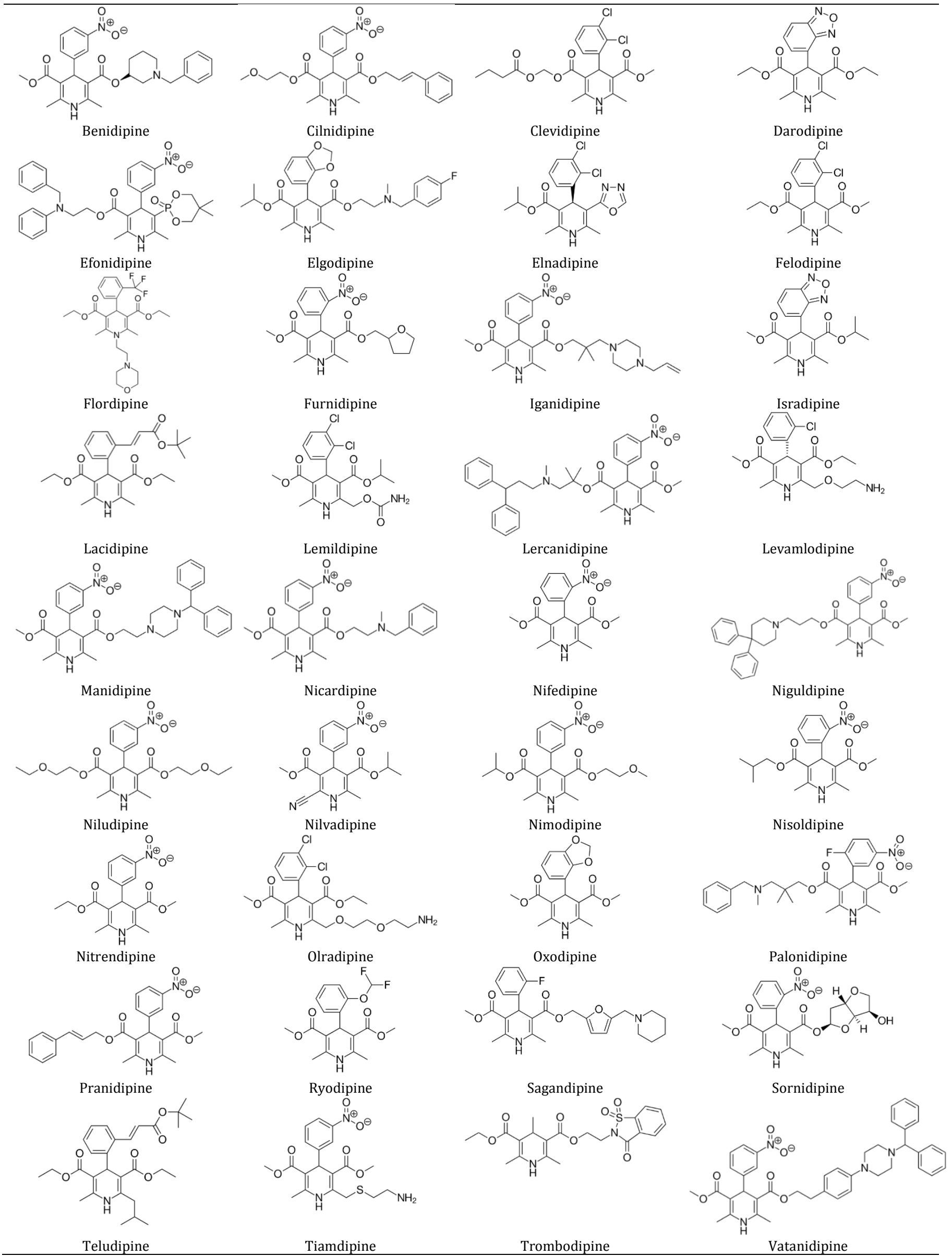




\section{Photochemistry of 1, 4-dihydropyridines}

The DHP drugs exhibit high sensitivity to light, undergoing a photo degradation process consisting, in most of the cases, in the oxidation of the dihydropyridine ring to pyridine derivative, as shown in fig. 1 $[8,9]$.<smiles>[R6]C1=C([R])C(c2cccc([R6])c2[R])C([R9])=C(C)N1</smiles>

Fig. 1: Photodegradation of DHP to pyridine derivative

In a limited number of DHPs, a more complex degradation has been demonstrated with the formation of secondary photoproducts. These molecular changes lead to loss of therapeutic effect or in some cases to toxic effects. Because of their high photo-lability in solution, almost all DHPs are dispensed in solid formulations, usually tablets, where the stability is significantly high $[10,11]$. Different analytical approaches have been proposed for the determination of DHPs in the presence of their photoproducts. The principal studies on the degradation mechanism common to most DHP drugs are described in this section. The analytical methods specific to each drug will be described in a later chapter.

The photochemistry of a series of DHPs bearing a substituent on the phenyl ring, as 4-(chlorophenyl) and 4-(4'-nitrophenyl) derivatives, was studied. All of these compounds underwent aromatization to give the pyridine by-products, devoid of any therapeutic effect. This process is initiated by proton transfer, probably to the solvent, from the excited singlet and is scarcely affected by the molecular oxygen. The presence of a nitro-group on the phenyl ring increases the process of aromatization because the delocalization of the negative charge is favorite, facilitating ionization and deprotonation [12].

Simultaneous determination of several DHPs and respective photoproducts was defined through a classical least squares (CLS) model built on the UV spectral data. A procedure for selecting the more useful wavelength ranges to use in calibration was also proposed. The good accuracy of the procedure was demonstrated by the recovery values over 97\% [13]. Photodegradation kinetics of nitrendipine and felodipine, exposed to UV and daylight in methanol solutions, was determined by processing the UV data in a selfmodeling multivariate curve resolution (MCR) method based on iterative target transformation and Kubista method. Concentration profiles and spectra of drugs and photoproducts were determined. The reaction was proved to be zero-order at the beginning of lighting, changing to a first-order when the concentration of photoproducts increased [14].

Light sensitivity of eleven DHPs was correlated against a series of molecular descriptors through a quantitative structure-property relationships (QSPR) model. The photodegradation rates, calculated from the spectral data collected throughout stressing photo degradation experiments, were combined with the values of the molecular descriptors by Partial Least Squares (PLS) analysis. The variables fitting the PLS model were selected and the resulting QSPR model was validated. The model was applied to other DHPs, showing good agreement between predicted and measured photodegradation rates [15]. Photodegradation of fifteen newly synthesized DHPs was monitored by spectrophotometry and the data processed by MCR analysis. This multivariate technique allowed to estimate the spectra and the concentration of the components involved in the degradation process. A single photoproduct was estimated from degradation of both DHPs, due to the aromatization of the pyridine ring. Traces of a second photoproduct were detected in twelve DHPs and a third photoproduct was verified only in one case. High stability was demonstrated when the fluorine group was in the position $R_{1}$ of the phenyl ring or simultaneously present in $\mathrm{R}_{1}$ and $\mathrm{R}_{2}$ positions. In contrast, the presence of chlorine in $\mathrm{R}_{1}$ or $\mathrm{R}_{2}$ strongly increased the degradation process [16]. In a second paper of the same Authors, six new condensed DHPs were synthesized by microwave irradiation method and submitted to forced photodegradation experiments. The formation of the oxidized pyridine derivative was observed for all the studied DHPs, except for one compound, which showed a very fast degradation and the formation of a second photoproduct [17].

\section{Photodegradation testing}

Research on drug photodegradation has considerably increased after 80s. Nowadays, the studies in this field have become an important issue in pharmaceutical research and a lot of papers, reviews or books on photo-labile drugs and their formulations continue to be published. The most important and studied effects from photodegradation of the drug are the formation of inactive or toxic products or photoallergic and photomutagenic effects [18-21]. In the last few years, chemical mechanisms and photodegradation kinetics have been described for a high number of drugs. Some reviews or books, published in the first decade of the twentieth century, deal very deeply with photolabile drugs and their formulation problems [22-24].

At present, it is compulsory for the pharmaceutical industry to conduct photoreactivity studies on drugs in formulation and packaging processes [25]. An overall stress testing for the new drugs is detailed in the rules ICH (International Conference on Harmonization), adopted since 1997 by the European Community, the United States and Japan. In particular, second part Q1B "Photostability testing of new drug substances and products" is an integral part of the overall stress testing [26]. The tests need to be performed on the pure drug substance and on the drug outside of the immediate pack. If necessary, other tests should be performed on both immediate and marketing packs. ICH rules include the optional use of two different light sources:

1) Any light source able to produce an output similar to the D65/ID65 emission standard. D65 is the standard for outdoor daylight and ID65 is the equivalent indoor indirect daylight standard.

2) A cool white fluorescent light source combined with a near ultraviolet lamp.

During the stress test, the temperature must be monitored to minimize any change caused by the light source. Photostability testing involves a first forced degradation test to evaluate the global photosensitivity of the drug, used for analytical aims, and a confirmatory testing to establish the information useful for drug handling, packaging and labeling. The use of solar radiation is not recommended because of its dependence on the geographical position and climate [25]. The ICH rules have been subject to criticism by some researchers. In 2010, Baertschi et al. discussed the application of ICH Guideline to conduct drug stability tests [27]. After that, other papers from the same Authors were published, detailing the conduction of the tests on various pharmaceutical forms $[28,29]$.

\section{Photodegradation studies on dihydropyridine drugs}

This chapter reports the main studies on photodegradation of a large number of DHPs. For some structures listed in table 1, no specific work on their photodegradation process has been published.

\section{Amlodipine}

Amlodipine is one of the most used DHPs to treat hypertension and prevent angina chest pain. The photo-lability of this drug has been well documented and several analytical methods have been proposed. A mechanistic study on the photodegradation of amlodipine besylate was carried out in water and in organic solvents. Irradiation caused aromatization with the formation of the pyridine by-product through an oxygen-independent process. The photo-lability of this drug was justified by the high absorption in the UV-A range [30]. A derivative spectrophotometric method was defined for the simultaneous determination of amlodipine and its pyridine photoproduct by correlating the concentrations of the analytes with the specific spectral signals in the third-order UV 
derivative spectrum. Recovery values from 95 to $99 \%$ and limit of quantitation (LOQ) of $1 \%$ for the by-product demonstrated the satisfactory validity of this method [31].

Since UV light is often used in water disinfection, amlodipine and other calcium antagonists (diltiazem and verapamil) were monitored in water under UV irradiation at $254 \mathrm{~nm}$. The photoproducts were separated by solid phase extraction (SPE) and identified to assess the potential ecological risks [32]. Still for environmental risk assessment, amlodipine photo degradation was studied under solar radiation and xenon lamp. Sixteen photoproducts were identified through chromatography with mass detector UHPLC-QTOF-MS. Some of them are secondary products originated in turn from the first pyridine derivative, which was the only photoproduct resulting in environmental waters and in sewage [33].

An RP-HPLC isocratic method was applied to amlodipine besylate solutions subjected to photodegradation as well as to acid and alkaline hydrolysis and chemical oxidation. After $14 \mathrm{~d}$ in an irradiation camera, the drug solution showed a degradation of $32.2 \%$ [34]. Photo stability of amlodipine was studied also in solid formulations. The tablets were exposed to light from a D65 lamp, according to ICH-Q1B rules, and photodegradation was monitored by HPLC using a reversed phase column with UV detection. Although much more slowly than the reaction in solution, photochemical reactions confirmed the aromatization of the dihydropyridine ring and the conversion of the nitro group to nitroso group [11].

\section{Aranidipine}

Aranidipine has good antihypertensive activity but its preferential use is in the therapy of angina pectoris [35]. The drug has shown photo-lability but only one study on the toxicity of the main photo degradation product in mice has been published. No toxic signs were observed during the observation period following administration of the photoproduct [36].

\begin{abstract}
Azelnidipine
Azelnidipine has been approved in Japan for the treatment of hypertension, with selectivity for L-type calcium channels. The antihypertensive efficacy of azelnidipine is similar to that of amlodipine or nitrendipine. It is usually well tolerated and its use is not associated with reflex tachycardia [37]. An RP-HPLC procedure was developed for the simultaneous determination of azelnidipine and olmesartan, as a stability-indicating method under forced degradation conditions (photolysis as well as hydrolysis and oxidation). Drug photostability was tested by exposing the drug in solid form to direct sunlight on summer days. Azelnidipine showed extensive degradation under all conditions but good stability when exposed to humidity [38]. As noted above, testing the photosensitivity of a drug under direct sunlight is of little value since natural conditions do not have standardized and repeatable features. However, this work is the only one dealing with the photodegradation of this drug.
\end{abstract}

\section{Barnidipine}

Barnidipine is a long-term DHP and its antihypertensive action is related to the reduction of peripheral vascular resistance secondary to its vasodilatory action [39]. An accurate study on the behavior of barnidipine when exposed to natural and stressing light irradiation was conducted, showing different photodegradation processes under these two light sources [40]. Kinetics of the process was determined by HPLC and spectrophotometry. Exposure of the drug to sunlight caused oxidation to give the pyridine derivative as the main photoproduct. In contrast, under stressing irradiation, a complex degradation pathway caused the formation of numerous by-products (fig. 2).

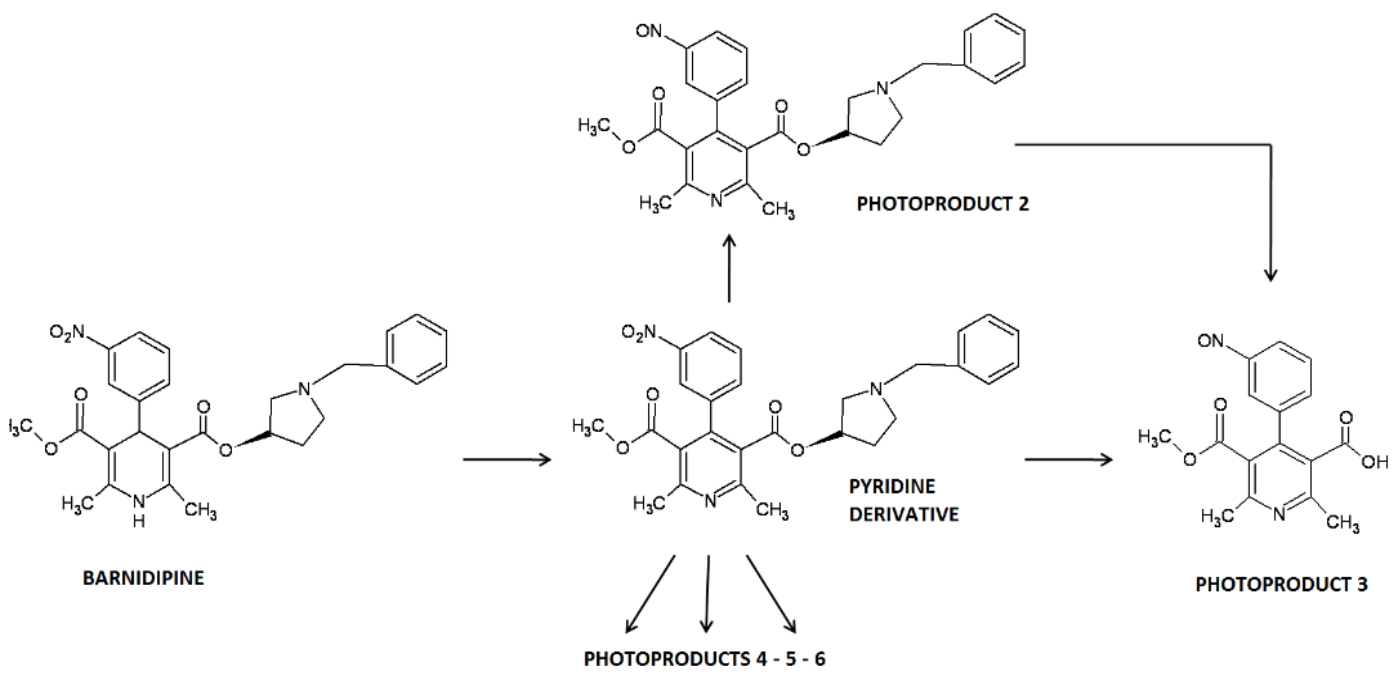

Fig. 2: Scheme of photodegradation mechanism of barnidipine

In another papers, four barnidipine impurities were detected by HPLC, then identified, synthesized, and subsequently characterized by their respective MS, $1 \mathrm{H}-\mathrm{NMR}$ and ${ }^{13} \mathrm{C}-\mathrm{NMR}$ spectral data $[41,42]$.

\section{Benidipine}

Determination of benidipine hydrochloride in pure form and pharmaceuticals was defined by a first-order derivative spectrophotometric method. Forced degradation studies were conducted by exposing the drug to stress conditions. Also for this drug, degradation leads to oxidation of the molecule with aromatization of the dihydropyridine ring. The procedure was validated according to the ICH guidelines with respect to accuracy, precision, linearity, limit of detection, LOQ [43].

\section{Cilnidipine}

A specific and highly sensitive stability indicating RP-HPLC method with photodiode array detection was developed for the estimation of cilnidipine in bulk and pharmaceutical formulations. Reliability and analytical performance of the method were validated for LOQ, linearity, precision, accuracy and specificity.

The drug was subdued to forced degradation under photolytic, acidic, basic, oxidative and thermal conditions and all degradation products were resolved. Photo degradation studies were conducted by exposing the drug to UV radiation. Three photoproducts were detected, but unidentified, and a degradation of $10.45 \%$ was calculated after $24 \mathrm{~h} \mathrm{[44]}$. 


\section{Clevidipine}

MS and NMR techniques were used for the structural characterization of eleven potential impurities of clevidipine butyrate, including process-related compounds and degradation products. An RP-HPLC method was developed to separate and quantify the impurities. Under light irradiation, the major degradation product was confirmed to be the pyridine derivative [45].

\section{Felodipine}

A stability indicating RP-HPLC method was developed for the assay of felodipine as a bulk drug and in pharmaceuticals. Separation of the drug peak from the peaks of the photodegradation products was satisfactory. No interference was relieved from the tablet excipients [46]. A different photo-physical and photochemical behavior was found between felodipine and nimodipine. Felodipine showed a major reactivity in its ground state towards electrophilic transient species like singlet oxygen. In contrast, nimodipine showed higher reactivity and photo-lability in the excited state. Felodipine is less photo-labile than nimodipine probably because of a lowered stability of the zwitterion radical involved in the photodegradation reaction. These results could be very useful to study the photoallergic and phototoxic effects from these drugs [47].

\section{Flordipine}

A comparative study was conducted on flordipine tablets exposed directly to light or covered with amber vinyl sheeting. The tablets were exposed to accelerated light conditions, under 150 foot candles of fluorescent light. The data demonstrated that the amber colored vinyl sheeting had an excellent protective effect on the discoloration of the tablets [48].

\section{Furnidipine}

Photodecomposition of furnidipine was studied byis UV spectrophotometry, HPLC and voltammetry under artificial daylight, UV light and room daylight. The daylight photoproduct was isolated and identified by NMR and IR as the nitrosophenyl-pyridine derivate. Quantitative kinetic data for the UV photodecomposition of furnidipine was not obtained due to a rate of degradation under 1 min. However, the nitrophenyl-pyridine by-product was identified as the main photoproduct [49].

\section{Isradipine}

The photochemical decomposition of isradipine was evaluated by calculating the photodegradation rate constant, the half-life period and the time of $10 \%$ degradation. The photodegradation process was assessed by UV spectrophotometry, HPLC and HPTLC chromatography. The formation of inclusion complexes of isradipine with M- $\beta C D$ was proved to increase twice the photostability of the drug [50].

\section{Lacidipine}

Photostability of lacidipine was studied in solutions exposed to UV-A radiations. Separation among the drug and its photoproducts was done by HPLC. The main photodegradation products were isolated and characterized [10]. The photodegradation mechanism proposed in this work (fig. 3) differs from those usually described for the other DHPs and consisted in a first isomerization followed by a cyclization involving both benzene and pyridine rings.

Another stability-indicating HPLC method was developed for the determination of lacidipine in the presence of its degradation products and applied to the analysis of the drug in bulk and in commercial tablets. The procedure was used to investigate the kinetics of photo-induced, alkaline and acidic degradation, confirming an apparent first-order rate constant [51]. The simultaneous determination of lacidipine and its main photoproduct, resulting from the cyclization reaction above described, was performed by applying the fractional wavelet transform (FWT) technique to the absorption spectra of the compounds. The resulting FWT spectra were processed by continuous wavelet transform (CWT) and multilinear regression calibration (MLRC).

The method was simple, rapid and not requiring any chemical separation [52]. The same binary mixture was analyzed by means of the "zero-crossing" technique in derivative spectrophotometry and the results compared with those from multivariate procedures. The chemometric methods demonstrated a better prediction ability, showing recovery of $101-103 \%$ and $96-98 \%$ for drug and degradation product, respectively. In contrast, the derivative spectrophotometric method suffered from the use of the signals along the slopes of the spectral curve, giving lower accurate and precise results [53].

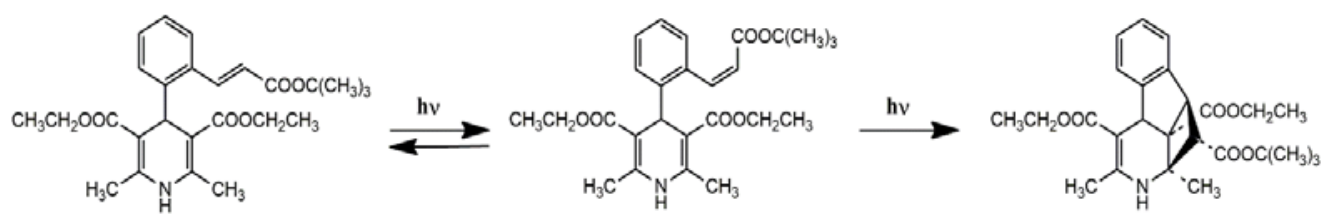

Fig. 3: Cis-isomerization and cyclization of lacidipine

\section{Lercanidipine}

The photo degradation process of lercanidipine was investigated by UV spectrophotometry and liquid chromatography. The drug and its main photoproducts were separated by HPLC and characterized by MS detection, using an electrospray ionization source (ESI) and an ion trap analyzer. The pathway of the process included a first aromatization of the dihydropyridine ring followed by the formation of nitroso-derivatives and $\mathrm{N}$-dealkylation in the side chain [54].

\section{Manidipine}

Determination of manidipine and its pyridine derivative was developed by applying a CLS regression method on the UV spectral data. This procedure was optimized by an appropriate selection of the most useful wavelength ranges. Quantification limit for the photoproduct concentration was estimated as 1.0\% [55]. Manidipine degradation under forced conditions, according to the ICH guidelines, was studied also using an HPLC method with UV and MS detection. A comprehensive degradation pathway and the identity of the major products were defined. The degradation kinetics could be best described as zero-order process [56].

\section{Nicardipine}

The simultaneous determination of nicardipine and its pyridine photoproduct was proposed by using a fourth-order derivative spectrophotometric method. The analytes concentrations were correlated with specific spectral measurements through equations obtained by simple and multiple regression analysis [57]. The photodegradation behavior of nicardipine was studied by HPLC under UV and daylight conditions and the main degradation product, identified as the pyridine analogue of the drug parent, was confirmed by mass spectrometry [58]. The two polymorph forms $\alpha$ and $\beta$-of nicardipine were studied by FTIR, X-ray diffraction analysis and differential scanning calorimetry to evaluate the photostability and other physicochemical properties. The solid form of the drug was also reported to be transformed into the pyridine derivative when exposed to light. The two crystalline forms changed to nearly amorphous form after irradiation grinding in a mixer mill. The 
apparent photodegradation rate constant of $\beta$-form was greater than that of $\alpha$-form [59].

\section{Nifedipine}

Nifedipine represents the lead of the DHP class and several papers have been published about its behavior under light. These studies have shown rapid photodegradation of the drug with the formation of two main photoproducts: the pyridine derivative from oxidation of the dihydropyridine ring and the nitroso derivative from the reduction of the nitro group. In the last years, degradation kinetics of nifedipine was studied by MCR, based on the combination of Kubista method and iterative target transformation method of Gemperline [60]. The spectra from degradation experiments were subjected to factor analysis revealing a photodecomposition kinetics of zeroorder with the formation of the nitroso-pyridine derivative as the major degradation product and the pyridine derivative in less content. The photodecomposition kinetics changed to a first-order when the nifedipine concentration reached a value of less than $50 \%$. Photostability of nifedipine was quantitatively analyzed by a photocalorimeter adopting light emitting diode (LED) arrays. Five LEDs were used to create an array from 360 to $700 \mathrm{~nm}$. The LEDs in this experiment operated individually in order to determine the wavelength responsible of the degradation, found to be $360 \mathrm{~nm}$ [61]. In a subsequent work, photodegradation experiments on nifedipine, monitored by DAD analysis, confirmed that the wavelengths responsible of degradation are in the spectral region $280-400 \mathrm{~nm}$. The formation of the pyridine and nitroso photoproducts was confirmed too, obeying a unimolecular mechanism [8]. In this work, a new reaction order (the so-called $\Phi$-order) was identified and proposed for unimolecular photodegradation reactions. The quantum yield of nifedipine was found to increase with irradiation wavelength and its photostability improved by increasing drug or excipients concentration. Stability studies on nifedipine in the solid state were monitored by $1 \mathrm{H}-14 \mathrm{~N}$ NMR-NQR double resonance (NQDR). The nitroso-nifedipine by-product was detected upon longterm daylight exposure. This photo-conversion was found to be accompanied with the electron density redistribution at the nitrogen sites [62].

\section{Nilvadipine}

Photodegradation of nilvadipine under UV light was found to cause the aromatization of the dihydropyridine ring and elimination of the HCN molecule, leading to the formation of three photoproducts. The exposure of nilvadipine to UV light was found to lead to aromatization of the DHP ring and elimination of HCN [63]. The experiments were monitored by GC-MS. In another work, the photochemical decomposition in methanol solution was performed under a high-pressure mercury arc lamp (300-400 nm). The experiments were monitored by UV spectrophotometry and HPLC. The two methods allowed the calculation of the kinetic parameters of photodegradation from the relationship $\ln c=f(t)$. The results obtained by HPLC and UV techniques did not show significant difference [64].

\section{Nimodipine}

A direct method for the simultaneous quantification of nimodipine and its pyridine derivative, as main photoproduct, was developed by using the derivative spectrophotometric technique. The results were compared with those obtained by gaschromatography [65]. The photochemical behavior of nimodipine was also studied in comparison with that of felodipine. Nimodipine resulted more photo-labile than felodipine, due to the presence of different substituents on the 4-phenyl moiety. The nitro group is probably responsible in the formation of the pyridine derivative as main photodegradation product [47].

\section{Nisoldipine}

Nisoldipine under daylight and UV light exposure gave the 4-(2nitrosophenyl) pyridine and pyridine photoproducts, under both irradiation conditions. The test was monitored by UV derivative spectrophotometry [66]. In contrast, another work about photodegradation of this drug in solid state reported the appearance of the nitroso-phenyl-pyridine photoproduct under daylight while the formation of nitro-phenyl-pyridine under UV light. The photodegradation kinetics of solid-state drug was considered to be zero-order reaction [67]. Separation of nisoldipine and photodegradation products was obtained by HPTLC on LiChrospher Si 60 F254s plates [68].

\section{Nitrendipine}

Estimation of stability to light of nitrendipine was defined by HPLC, HPTLC and spectrophotometry, in both acidic and alkaline media. Photodegradation was found faster in acidic medium, following a first-order kinetics. The dehydro-nitrendipine was confirmed as the main degradation product [58]. These results were confirmed in another work in which nitrendipine and dehydro-nitrendipine were well resolved in the HPLC chromatogram $[69,70]$. The simultaneous quantification of nitrendipine and photoproduct was proposed by using third-order derivative spectrophotometry and gaschromatography [71]. Photodegradation kinetics was also studied by self-modeling curve resolution method applied on the UV spectral data, combining iterative target transformation and Kubista method. This multivariate procedure allowed to estimate concentration profiles and pure spectra of the components involved in the photodegradation process [14].

\section{Trombodipine}

Photostability and phototoxic potential of a new 4-alkyl-1,4dihydropyridine, namely trombodipine, were investigated by using a multilamp photoreactor centered at $350 \mathrm{~nm}$. The drug exhibited a slow photodegradation, showing first-order kinetics that decreased in the absence of oxygen. Irradiation of red blood cells and Hep-2 (human larding carcinoma cell line) did not show phototoxic effects [72].

\section{Photodegradation of dihydropyridines in biological samples}

Appropriate precautions for storage and handling of plasma samples containing DHPs should be adopted so to avoid the photodecomposition of the analytes. To investigate this topic, photostability of eleven DHPs was monitored in spiked plasma samples exposed to laboratory light. The screening procedure was performed by analyzing the samples by LC-MS-MS. Nifedipine and nisoldipine were reduced by $75 \%$ in just $2 \mathrm{~h}$. In a manner similar to in vitro reactions, the pyridine analogue resulted as the main degradation product, referred also as the first metabolite in the metabolic pathway. Lercanidipine and nicardipine showed further ester hydrolysis after this first oxidation reaction. Several additional minor degradation products were found for the other drugs [73].

With the aim to define the most adequate conditions for handling nifedipine solutions in the analytical laboratory, a micellar LC method was proposed to reduce the drug degradation in different biological matrices, such as serum and urine. This method was shown to increase the stability of nifedipine, thus preventing photodegradation and allowing the direct analysis of biological samples. This procedure did not show interferences or matrix effects produced by endogenous compounds [74].

\section{Photosensitivity and photoxicity of dihydropyridines drugs}

It is known that some drugs that easily react to light can cause phototoxic skin responses even after systemic administration. The drug or its metabolites can act as chromophores and absorb energy from light, turning into an "excited" state with high energy content. When the molecules return to the fundamental state, the absorbed energy is transferred to neighboring tissues causing damage. Free radicals or toxic photoproducts that can damage DNA or cell membranes can be also formed. This problem has been deepened for DHP drugs in an interesting work of 2007 [47], where a series of drugs of this class were exposed to artificial light, showing a significant production of singlet oxygen, superoxide or both. The formation of these species indicated the potential photosensitivity that could lead to phototoxic dermatitis. In the same work, the photochemical behavior of felodipine and nimodipine was compared. Both compounds were able to generate singlet oxygen, however nimodipine was more photo-labile in excited state, while felodipine showed a major reactivity in its ground state. The results showed the difficulty in discriminating which specie is 
responsible for the photoallergic and phototoxic effects, because these effects could be attributed to the participation of zwitterionic radicals in the photodegradation process and/or to ability in generating singlet oxygen. In another work, the photosensitizing properties of dihydropyridine drugs, with regard to bradykinin $\mathrm{B}_{2}$ receptor antagonist activity, were evaluated by monitoring the reactive oxygen species (ROS) generated from the compounds irradiated with UV light. The production of singlet oxygen and superoxide were confirmed, with a potential peroxidation of fatty acids that could lead to phototoxic dermatitis. The addition of radical scavengers, such as butylated hydroxyanisole, reduced glutathione and N-(2-mercaptopropionyl) glycine (MPG) and seemed to attenuate the lipid peroxidation, suggesting so the involvement of ROS in promoting the occurrence of phototoxic processes [75].

\section{Photostabilization approaches}

Because of instability to light, almost all DHP antihypertensive are marketed in solid pharmaceutical formulations. Several studies have been proposed or have been undertaken to define new formulations or to design other technological systems able of providing valid photoprotection for these drugs. At present, only few specialties are marketed in solution form, packaged in amber glass containers or other completely opaque materials.

The photoprotective effect of a series of containers in different glassy or polymeric matrices was investigated with regard to four DHPs in solution, felodipine, lercanidipine, nimodipine, nifedipine [76]. The samples were submitted to stress test under Xenon lamp and the experiments were monitored by UV spectrophotometry. The spectral data were elaborated by MCR, able to estimate the kinetic parameters and resolve the spectra of the components involved in the photodegradation process. Polyethylene terephthalate (PET) containers proved to give a significant photoprotection for all drugs. The best result was reached for the felodipine solution in transparent blue PET, showing complete stabilization up to six hours under stressing irradiation. The amber glass containers did not provide analogous photoprotection. These results sound very interesting to design liquid dosage forms of DHPs as an alternative to the solid forms. Another approach increasing the photostability of the DHP specialties is the addition of light absorbing excipients, usually presenting absorption spectra similar to those of the drugs. Even the presence of antioxidants has gained good results. The influence of $\beta$-carotene on the photostability of nisoldipine was studied in stressing conditions, using a high-pressure mercury lamp as irradiation source. The photodegradation process was monitored by UV spectrophotometry and HPLC. The degradation rate constant of a methanol solution of nisoldipine decreased as $\beta$-carotene concentration increased, confirming the role of this excipient as photoprotective agent [77].

Over the last few years, great interest aroused the supramolecular matrices, which are able to incorporate a high number of drugs through non-covalent bonds, even if they are difficult soluble in other systems. The most famous of these complex matrices are the "self-assembled" structures, of which the liposomes are the most representative, and the "host-guest systems", among which the most famous "hosts" are the cyclodextrins (CD) [78, 79]. A series of DHPs were incorporated in liposomes and $\mathrm{CD}$ and the ability of the resulting complexes in protecting from light was investigated. Optimal photoprotection of all the drugs was demonstrated for both the systems. Only manidipine and lercanidipine showed not satisfactory results, due to the low inclusion in the supramolecular matrices [80]. Inclusion complexes of felodipine in $\beta-C D$ was obtained in a binary or ternary system with addition of polyethylene glycol 6000. Solubility of felodipine increased 10 fold in liquid threecomponent complexes. The complexes were studied by IR spectroscopy, differential scanning calorimetry and 13C-NMR. Complexation of the drug with $\beta$-CD caused a two-fold increase of the photodegradation rate if compared with its crystalline form [81].

Photostability of amlodipine was monitored after incorporation in $\mathrm{CD}$, liposomes and microspheres. The photodegradation process was conducted according to the ICH Guideline and monitored by spectrophotometry. After a radiant exposure of $11,340 \mathrm{~kJ} \mathrm{~m}^{-2}$, all the formulations were found to increase drug stability, with a residual drug concentration of 90 and 77\% in CD and liposomes, respectively, and an excellent value of $97 \%$ in microspheres [82]. A dry oil-inwater emulsion was prepared, using labrafil M1944CS and dextrin, to improve the photostability of amlodipine. This formulation greatly improved the photostability of the drug and at the same time increased its bioavailability. The photodegradation study proved that $94.4 \%$ of amlodipine remained intact after 24 -h UV irradiation versus $33.1 \%$ as powder [83]. Photostability of felodipine in (2hydroxypropyl)- $\beta$-CD was studied in presence of water soluble polymers as polyvinylpyrrolidone, polyethylene glycol and hydroxypropyl-methylcellulose. Drug solubility resulted very improved and, at the same time, a dramatic decrease in degradation rate constants of the drug-in-CD complex was observed [84]. The photochemical behavior of nimodipine and felodipine was evaluated when incorporated in biological-mimicking systems like micelles or liposomes. The micelles were formed by using ionic or nonionic surfactants, as sodium dodecyl sulfate, dodecyl-pyridinium chloride and mono lauryl sucrose ester, in order to study the influence of the surface charge in modulating the photo-reactivity of these drugs. Both drugs were demonstrated to be located near to the interface but the photodegradation rate did not change with the surface charge [85].

Barnidipine photostability was investigated in $\mathrm{CD}$ or liposome matrices and in appropriate combinations of these matrices, as an alternative to the current solid specialties. The drug was subdued to photodegradation stressing tests and monitored by derivative spectrophotometry. The residual concentration of the drug in liposome and CD matrices was 42.90 and $72.03 \%$, respectively, after a radiation exposure of $225 \mathrm{kJm}^{-2}$. This value reached the value of $90.78 \%$ when the drug-CD complex was in turn entrapped in liposomes, very close to that calculated in tablets (96.03\%) [86]. Incorporation of isradipine in $\mathrm{CD}$ has been exposed in several papers. Isradipine is a highly hydrophobic drug and is practically insoluble in water. Incorporation in supramolecular matrices were aimed to both increase its solubility and photostability. Differential scanning calorimetry and X-ray diffraction were adopted to study the physicochemical properties of the inclusion complexes of isradipine in $\beta$-CD. The first aim of this work was to develop isradipine formulations able to increase the passage of the drug through the buccal membrane. Isradipine in these complexes resulted more stable than pure drug [87]. Isradipine was also chosen to prepare sustained release hydroxypropylmethyl-cellulose tablets containing inclusion complex of the drug in $\beta$-CD. The physicochemical properties of the complexes and solubility tests were measured by differential scanning calorimetry and FTIR. Photostability of the drug in the complex was more stable than pure isradipine up to four days radiation [88]. The process of photodegradation of isradipine incorporated in methyl- $\beta$-CD was also studied by UV spectrophotometry, HPLC and HPTLC. Photodegradation rate constant $(\mathrm{k})$, half-life period $\left(\mathrm{t}_{0.5}\right)$ and time of degradation of $10 \%\left(\mathrm{t}_{0.1}\right)$ were calculated. Inclusion in CD increased twice the photostability of the drug [50]. Incorporation of nicardipine in $\mathrm{CD}$ was evaluated in terms of photostability in aqueous solution under exposure to UV(A)-UV(B) radiations. The photodegradation process was monitored by capillary electrophoresis using $(2,3,6$-tri-0-methyl)- $\beta$-CD as chiral selector, able to provide the enantio-resolution of the nicardipine enantiomers. Photostability was estimated for the inclusion complexes of the racemic nicardipine with $\alpha-C D, \beta-C D, \gamma-C D$, hydroxypropyl- $\alpha-C D$, hydroxypropyl- $\beta-C D$, hydroxypropyl- $\gamma-C D$, (2hydroxyethyl)- $\beta-C D$ and methyl- $\beta-C D$. The matrices studied showed satisfactory photoprotective effect. In contrast, $\alpha$-CD was found to favor drug photodegradation. Two distinct photo-degradation profiles, with relative kinetic constants $(\mathrm{k})$, were observed for the nicardipine enantiomers only for the $\beta$-CD complex [89].

The use of polymers for supramolecular matrices is a recent approach, but they are already experiencing a wide application success. Incorporation systems represented by polymer-based microspheres or microcapsules are widely studied in controlled release systems. Microspheres are spherical particles of micron size, typically prepared using natural or synthetic polymers. Microspheres allow continuous drug concentration with a corresponding decrease in single dose and a reduced frequency of 
administration. Polymeric nanocapsules containing nifedipine were prepared with the aim to preserve the drug from degradation. The surfactants pluronic F68 and polyvinyl alcohol were used to prepare the nanocapsule suspensions. The solid drug and the nanocapsules were submitted to light exposure. Particle size, zeta potential and entrapment efficiency remained constant during a period of $28 \mathrm{~d}$ under light exposure. The pure drug was completely degraded after $4 \mathrm{~d}$ while the percentage of drug remaining in the nanocapsules was around $25-30 \%$, suggesting a significant protection of the drug into this matrix [90]. Porous calcium silicate was evaluated for increasing the photostability of nifedipine in a solid dispersion formulation.
This formulation was more stable to light irradiation than a classical formulation of the drug in microcrystalline cellulose. The photoprotection was hypothesized to be due to the physical shielding against light [91]. Another approach to improve the stability of nifedipine was proposed by complexation with weak cation-exchange resins, indion 204 and indion 264.

The tablets were subdued to artificial light and indirect sunlight and the results compared with those from pure drug. Indion 204 was found to be a valid complexing agent for reducing the photosensitivity of nifedipine in tablets [92].

Table 2: Main studies about photodegradation and photostabilization of DHPs

\begin{tabular}{|c|c|c|}
\hline DHP & Photodegradation studies & Photostabilization studies \\
\hline Amlodipine & $\begin{array}{l}\text { Kawabe et al., } 2008 \text { [11]. } \\
\text { Fasani et al., } 2008 \text { [30]. } \\
\text { Ragno et al., } 2002 \text { [31]. } \\
\text { Zhu et al., } 2015 \text { [32]. } \\
\text { Jakimska et al., } 2014 \text { [33]. } \\
\text { Stoiljkovic et al., } 2014 \text { [34]. }\end{array}$ & $\begin{array}{l}\text { Ragno et al., } 2003 \text { [83]. } \\
\text { Jang et al., } 2006 \text { [84]. }\end{array}$ \\
\hline Aranidipine & $\begin{array}{l}\text { Ohashi and Ebihara, 1996 [35]. } \\
\text { Kuwata et al., } 1993 \text { [36]. }\end{array}$ & \\
\hline Azelnidipine & Patel and Patel, 2014 [38]. & \\
\hline Barnidipine & $\begin{array}{l}\text { Ioele et al., } 2010 \text { [40]. } \\
\text { Cheng et al., } 2014 \text { [42]. }\end{array}$ & Ioele et al., 2014 [86]. \\
\hline Benidipine & Karasaka, 2015 [43]. & \\
\hline Cilnidipine & Kadam et al., 2015 [44]. & \\
\hline Clevidipine & Zhou et al., 2015 [45]. & \\
\hline Felodipine & $\begin{array}{l}\text { Javidnia et al., } 2008 \text { [14]. } \\
\text { Cardoza and Amin, } 2002 \text { [46]. } \\
\text { Pizarro et al., } 2007 \text { [47]. }\end{array}$ & $\begin{array}{l}\text { De Luca et al., } 2016 \text { [76]. } \\
\text { Mielcarek, } 1998 \text { [81]. } \\
\text { Narkhede et al., } 2011 \text { [84]. } \\
\text { Brito et al., } 2012 \text { [85]. }\end{array}$ \\
\hline Flordipine & Narurkar et al., 1986 [48]. & \\
\hline Furnidipine & Núñez-Vergara et al., 1994 [49]. & \\
\hline Isradipine & Mielcarek and Daczkowska, 1999 [50]. & $\begin{array}{l}\text { Mielcarek and Daczkowska, } 1999 \text { [50]. } \\
\text { Himabindu et al., 2013 [88]. } \\
\text { Park et al., } 2013 \text { [89]. }\end{array}$ \\
\hline Lacidipine & $\begin{array}{l}\text { De Filippis et al., } 2002 \text { [10]. } \\
\text { Belal et al., } 2009 \text { [51]. } \\
\text { Dinç et al., } 2012 \text { [52]. } \\
\text { Ragno et al., } 2006 \text { [53]. }\end{array}$ & \\
\hline Lercanidipine & Fiori et al., 2006 [54]. & De Luca et al., 2016 [76]. \\
\hline Manidipine & $\begin{array}{l}\text { Ragno et al., } 2003 \text { [55]. } \\
\text { Todeschini et al., } 2015 \text { [56]. }\end{array}$ & \\
\hline Nicardipine & $\begin{array}{l}\text { Ragno and Vetuschi, } 1998 \text { [57]. } \\
\text { Bonferoni et al., } 1992 \text { [58]. } \\
\text { Teraoka et al., } 2004 \text { [59]. }\end{array}$ & Pomponio et al., 2004 [89]. \\
\hline Nifedipine & $\begin{array}{l}\text { Maafi and Maafi, } 2013 \text { [8]. } \\
\text { Shamsipur et al., } 2003 \text { [60]. } \\
\text { Dhuna et al., } 2008 \text { [61]. } \\
\text { Latosińska et al., } 2012 \text { [62]. }\end{array}$ & $\begin{array}{l}\text { Tagliari et al., } 2015 \text { [90]. } \\
\text { Fujimoto et al., } 2016 \text { [91]. } \\
\text { Shende and Markandeeywar, } 2010 \text { [92]. }\end{array}$ \\
\hline Nilvadipine & $\begin{array}{l}\text { Mielcarek et al., } 2000 \text { [63]. } \\
\text { Augustyniak et al., } 2001 \text { [64]. }\end{array}$ & \\
\hline Nimodipine & $\begin{array}{l}\text { Ragno et al., } 1995 \text { [65]. } \\
\text { Pizarro et al., } 2007 \text { [47]. }\end{array}$ & Brito et al., 2012 [85]. \\
\hline Nisoldipine & $\begin{array}{l}\text { Marinkovic et al., } 2000 \text { [66]. } \\
\text { Marinkovic et al., } 2003 \text { [67]. } \\
\text { Agbaba et al., } 2004 \text { [68]. }\end{array}$ & Mielcarek et al., 2005 [77]. \\
\hline Nitrendipine & $\begin{array}{l}\text { Javidnia et al., } 2008 \text { [14]. } \\
\text { Tipre and Vavia, } 2001 \text { [69]. } \\
\text { Álvarez-Lueje et al., } 2002 \text { [70]. } \\
\text { Ragno et al., } 1993 \text { [71]. }\end{array}$ & \\
\hline Trombodipine & Cortés et al., 1993 [72]. & \\
\hline
\end{tabular}

\section{Conclusions and future developments}

Drug photostability has become an emerging topic in pharmaceutical research after the discovery of a high number of light-sensitive drugs and the possibility of phototoxic effects. At present, the pharmaceutical industry is obliged to test the photostability of the new drugs by following appropriate international guidelines to verify any changes after exposure to light. Unfortunately, all antihypertensive drugs belonging to the DHP class, which are the most used drugs for antihypertensive therapy, have a particular light sensitivity, completely losing therapeutic activity when degraded. For this reason, many analytical techniques, especially chromatographic and spectrophotometric, have been proposed to monitor the stability of these drugs. Understanding the kinetics and 
the reaction mechanism can be useful for the synthesis of novel photostable molecules or to define formulations that can minimize their photodegradation.

The most modern studies seek to overcome the adoption of traditional dark or opaque containers with the use of excipients, able to absorb visible and UV wavelengths, or of supramolecular matrices. The matrices that have so far shown the best results are liposomes or niosomes and cyclodextrins. These systems are able of incorporating drugs of different solubility and magnitude. One of the major benefits that can be obtained from these studies will be the formulation of DHPs in solution, which is currently absent because of their high photodegradation rate in solution form.

The increase in photostability of DHPs can also be pursued with targeted changes in their molecular structure. Some studies report condensed ring systems carrying 1,4-DHP structure, such as hexahydroquinolines, indenopyridines, acridines and furoquinolines. Also cyclopentane, cyclohexane or tetra-hydro-thiophene rings fused to the DHP ring seem influence both activity and photostability of such compounds. The electronic nature of substituents attached to the 4-aryl moiety of 1,4-dihydropyridines was demonstrated to strongly affect the photophysical and photochemical behavior of DHPs. The presence of an electron donor substituent on the 4-aryl moiety decreased the photodecomposition quantum yields. The same result was reached with the absence of electron-withdrawing substituents. In addition, the adoption of specific QSPR mathematical models, correlating the molecular substituents versus the photodegradation rate, may be of great utility to draw photostable molecules.

\section{ACKNOWLEDGMENT}

The authors thank Ministero Istruzione Università Ricerca (MIUR), Italy, for the financial support, grant 2016.

\section{AUTHORS CONTRIBUTIONS}

All the author have contributed equally

\section{CONFLICT OF INTERESTS}

Declared none

\section{REFERENCES}

1. Elliott WJ, Ram CVS. Calcium channel blockers. J Clin Hypertens 2011;13:687-9.

2. St-Onge M, Dube PA, Gosselin S, Guimont C, Godwin J, Archambault PM, et al. Treatment for calcium channel blocker poisoning: a systematic review. Clin Toxicol 2014;52:926-44.

3. Tamargo J, Ruilope LM. Investigational calcium channel blockers for the treatment of hypertension. Expert Opin Investig Drugs 2016;25:1295-309.

4. Tocci G, Battistoni A, Passerini J, Musumeci MB, Francia P, Ferrucci A, et al. Calcium channel blockers and hypertension. J Cardiovasc Pharmacol Ther 2015;20:121-30.

5. Khedkar SA, Auti PB. 1, 4-Dihydropyridines: a class of pharmacologically important molecules. Mini Rev Med Chem 2014;14:282-90.

6. Coca A, Mazon P, Aranda P, Redon J, Divison JA, Martínez J, et al. Role of dihydropyridinic calcium channel blockers in the management of hypertension. Expert Rev Cardiovasc Ther 2013;11:91-105.

7. Carosati E, Ioan P, Micucci M, Broccatelli F, Cruciani G, Zhorov $\mathrm{BS}$, et al. 1,4-Dihydropyridine scaffold in medicinal chemistry, the story so far and perspectives (part 2): action in other targets and antitargets. Curr Med Chem 2012;19:4306-23.

8. Maafi W, Maafi M. Modelling nifedipine photodegradation, photostability and actinometric properties. Int J Pharm 2013;456:153-64.

9. Vetuschi C, Ragno G, Veronico M, Risoli A, Gianandrea A. Comparative evaluation of analytical methods for simultaneous determination of nisoldipine and its photodegradation products. Anal Lett 2002;35:1327-39.

10. De Filippis P, Bovina E, Da Ros L, Fiori J, Cavrini V. Photodegradation studies on lacidipine in solution: basic experiments with a cis-trans reversible photoequilibrium under UV-A radiation exposure. J Pharm Biomed Anal 2002;27:803-12.

11. Kawabe Y, Nakamura H, Hino E, Suzuki S. Photochemical stabilities of some dihydropyridine calcium-channel blockers in powdered pharmaceutical tablets. J Pharm Biomed Anal 2008;47:618-24.

12. Fasani E, Albini A, Mella M. Photochemistry of hantzsch 1,4dihydropyridines and pyridines. Tetrahedron 2008;64:3190-6.

13. Ragno G, Vetuschi C, Risoli A, Ioele G. Application of a classical least-squares regression method to the assay of 1,4dihydropyridine antihypertensives and their photoproducts. Talanta 2003;59:375-82.

14. Javidnia K, Hemmateenejad B, Miri R, Saeidi-Boroujeni M. Application of a self-modeling curve resolution method for studying the photodegradation kinetics of nitrendipine and felodipine. J Pharm Biomed Anal 2008;46:597-602.

15. Ioele G, De Luca M, Oliverio F, Ragno G. Prediction of photosensitivity of 1,4-dihydropyridine antihypertensives by quantitative structure-property relationship. Talanta 2009;79: 1418-24.

16. Ioele G, Gunduz MG, De Luca M, Simsek R, Safak C, Muzzalupo R, et al. Photodegradation studies of 1,4-dihydropyridine compounds by MCR analysis on UV spectral data. Future Med Chem 2016;8:107-15.

17. Gunduz MG, Ragno G, Simsek R, De Luca M, Safak C, Grande F, et al. Synthesis and photodegradation studies of analogues of muscle relaxant 1,4-dihydropyridine compounds. Acta Pharm 2017;67:341-55.

18. Zaheer MR, Gupta A, Iqbal J, Zia Q Ahmad A, Roohi OM, et al. Molecular mechanisms of drug photodegradation and photosensitization. Curr Pharm Des 2016;22:768-82.

19. Altannak NF. Liquid chromatography-mass spectrometry method to assess naloxone hydrochloride photostability under artificial light and sunlight exposure at room temperature. Asian J Pharm Clin Res 2015;8:290-2.

20. Kapavarapu S, Mopidevi N, Chintala R. Forced degradation studies and reversed-phase high-performance liquid chromatographic method validation for the determination of ceritinib in bulk and its pharmaceutical dosage form. Asian J Pharm Clin Res 2015;8:44-51.

21. Naveed S, Uroog S, Waheed N. Degradation studies of different brands of moxifloxac in available in the market. Int J Curr Pharm Res 2015;5:110-6.

22. Albini A, Fasani E. Drugs photochemistry and photostability, The Royal Society of Chemistry, Cambridge (UK); 1998.

23. Piechocki JT, Thoma K. Pharmaceutical photostability and stabilization technology. CRC Press: New York; 2006.

24. Tønnesen HH. Formulation and stability testing of photolabile drugs. Int J Pharm 2001;225:1-14.

25. Tønnessen HH. Photostability of drugs and drug formulations. CRC Press; 2010. p. 435.

26. ICH Q1B Guideline Photostability Testing of New Drug Substances and Products Comments for its Application. Fed Regist; 1996. p. 62.

27. Baertschi SW. A critical assessment of the ICH guideline on photostability testing of new drug substances and products (Q1B): recommendation for revision. J Pharm Sci 2010;99:2934-40.

28. Baertschi SW, Clapham D, Foti C, Kleinman MH, Kristensen S, Reed RA, et al. Implications of in-use photostability: proposed guidance for photostability testing and labeling to support the administration of photosensitive pharmaceutical products, part 1: drug products administered by injection. J Pharm Sci 2013;2:3888-99.

29. Baertschi SW, Clapham D, Foti C, Kleinman MH, Kristensen S, Reed RA, et al. Implications of in-use photostability: proposed guidance for photostability testing and labeling to support the administration of photosensitive pharmaceutical products, part 2: topical drug product. J Pharm Sci 2015;104:2688-701.

30. Fasani E, Albini A, Gemme S. Mechanism of the photochemical degradation of amlodipine. Int J Pharm 2008;352:197-201.

31. Ragno G, Garofalo A, Vetuschi C. Photodegradation monitoring of amlodipine by derivative spectrophotometry. J Pharm Biomed Anal 2002;27:19-24. 
32. Zhu B, Zonja B, Gonzalez O, Sans C, Perez S, Barcelo D, et al. Degradation kinetics and pathways of three calcium channel blockers under UV irradiation. Water Res 2015;86:9-16.

33. Jakimska A, Sliwka-Kaszynska M, Nagorski P, Namiesnik J, KotWasik A. Phototransformation of amlodipine: degradation kinetics and identification of its photoproducts. Morishita $\mathrm{R}$ Plos One 2014;9:e109206.

34. Stoiljkovic Z, Jadranin M, Djuric S, Petrovic S, Ivic A, Mijin D. Investigation of forced and total degradation products of amlodipine besylate by liquid chromatography and liquid chromatography-mass spectrometry. Chem Ind Chem Eng Q 2014;20:295-304.

35. Ohashi K, Ebihara A. Aranidipine (MPC-1304), a new dihydropyridine calcium antagonist: a review of its antihypertensive action. Cardiovasc Drug Rev 1996;14:1-16.

36. Kuwata M, Tanaka G, Kashihara A, Hasegawa H, Morita K. Single dose toxicity studies of main metabolites and a photodegradation product of MPC-1304 in mice. Jpn Pharmacol Ther 1993;21:939-45.

37. Wellington K, Scott LJ. Azelnidipine. Drugs 2003;63:2613-21.

38. Patel JK, Patel NK. Validated stability-indicating RP-HPLC method for the simultaneous determination of azelnidipine and olmesartan in their combined dosage form. Sci Pharm 2014;82:541-54.

39. Malhotra HS, Plosker GL. Barnidipine. Drugs 2001;61:989-98.

40. Ioele G, Oliverio F, Andreu I, De Luca M, Miranda MA, Ragno G. Different photodegradation behavior of barnidipine under natural and forced irradiation. J Photochem Photobiol A 2010;215:205-13.

41. Ioele G, Luca M De. Assessment of acute toxicity and synergic effect of drugs in water. Bioluminescence Test 2014;39:1190-8.

42. Cheng ZG, Dai XY, Li LW, Wan Q, Ma X, Xiang GY. Synthesis and characterization of impurities of barnidipine hydrochloride, an antihypertensive drug substance. Molecules 2014;19:1344-52.

43. Karasaka A. First order derivative spectrophotometric method for the determination of benidipine hydrochloride pharmaceutical preparations and forced degradation study. Opt Spectrosc 2015;118:1002-6.

44. Kadam A, Hamrapurkar P, Patil S, Manoharan M, Suryagandha A. Development and validation of stability indicating RP-HPLC method for the estimation of cilnidipine in bulk and pharmaceutical dosage form. Int J Pharm Sci Rev Res 2015;30:177-81.

45. Zhou Y, Zhou F, Yan F, Yang F, Yao Y, Zou Q. Structural analysis and quantitative determination of clevidipine butyrate impurities using an advanced RP-HPLC method. J Chromatogr Sci 2016;54:353-60.

46. Cardoza RM, Amin PD. A stability indicating LC method for felodipine. J Pharm Biomed Anal 2002;27:711-8.

47. Pizarro N, Gunther G, Nunez-Vergara LJ. Photophysical and photochemical behavior of nimodipine and felodipine. J Photochem Photobiol A 2007;189:23-9.

48. Narurkar AN, Sheen PC, Bernstein DF, Augustine MA. Studies on the light stability of flordipine tablets in amber blister packaging material. Drug Dev Ind Pharm 1986;12:1241-7.

49. Nunez-Vergara LJ, Sunkel C, Squella JA. Photodecomposition of a new 1,4-dihydropyridine: furnidipine. J Pharm Sci 1994;83:502-7.

50. Mielcarek J, Daczkowska E. Photodegradation of inclusion complexes of isradipine with methyl- $\beta$-cyclodextrin. J Pharm Biomed Anal 1999;21:393-8.

51. Belal F, Elbrashy A, Eid M, Nasr JJ. Stability-indicating LC method for the determination of lacidipine in tablets application to degradation kinetics and content uniformity testing. Chromatographia Vieweg Verlag 2009;69:1201-9.

52. Dinc E, Ragno G, Baleanu D, De Luca M, Ioele G. Fractional wavelet transform-continous wavelet transform for the quantification of melatonin and its photodegradation product. Spectrosc Lett 2012;45:337-43.

53. Ragno G, Ioele G, De Luca M, Garofalo A, Grande F, Risoli A. A critical study on the application of the zero-crossing derivative spectrophotometry to the photodegradation monitoring of lacidipine. J Pharm Biomed Anal 2006;42:39-45.

54. Fiori J, Gotti R, Bertucci C, Cavrini V. Investigation on the photochemical stability of lercanidipine and its determination in tablets by HPLC-UV and LC-ESI-MS/MS. J Pharm Biomed Anal 2006;41:176-81.

55. Ragno G, Vetuschi C. UV derivative spectrophotometric assay of nicardipine and its photodegradation product. Pharmazie 1998;53:628-31.

56. Ragno G, Aiello F, Garofalo A, Ioele G, Sinicropi MS. Multivariate least squares regression applied to the spectrophotometric analysis of manidipine and its main photoproduct. Il Farmaco 2003;58:909-15.

57. Todeschini V, Sangoi M da S, Goelzer GK, Andrade JM de M, Volpato NM. Delapril and manidipine main degradation products: LC-UV and LC-ESI-MS evaluations, decay kinetic, and in vitro cytotoxicity studies. J Liq Chromatogr Relat Technol 2015;38:1333-42.

58. Bonferoni MC, Mellerio G, Giunchedi P, Caramella C, Conte U. Photostability evaluation of nicardipine $\mathrm{HCl}$ solutions. Int J Pharm 1992;80:109-17.

59. Teraoka R, Otsuka M, Matsuda Y. Evaluation of photostability of solid-state nicardipine hydrochloride polymorphs by using Fourier-transformed reflection-absorption infrared spectroscopy-effect of grinding on the photostability of crystal form. Int J Pharm 2004;286:1-8.

60. Shamsipur M, Hemmateenejad B, Akhond M, Javidnia K, Miri R. A study of the photo-degradation kinetics of nifedipine by multivariate curve resolution analysis. J Pharm Biomed Anal 2003;31:1013-9.

61. Dhuna M, Beezer AE, Connor JA, Clapham D, Courtice C, Frost J, et al. LED-array photocalorimetry: Instrument design and application to photostability of nifedipine. J Pharm Biomed Anal 2008;48:1316-20.

62. Latosinska JN, Latosinska M, Seliger J, Zagar V. An innovative method for the non-destructive identification of photodegradation products in solid state: $1 \mathrm{H}-14 \mathrm{~N}$ NMR-NQR and DFT/QTAIM study of photodegradation of nifedipine (antihypertensive) to nitrosonifedipine (potential anti-oxidative). Eur J Pharm Sci 2012;47:97-107.

63. Mielcarek J, Stobiecki M, Frański R. Identification of photodegradation products of nilvadipine using GC-MS. J Pharm Biomed Anal 2000;24:71-9.

64. Augustyniak W, Mielcarek J, Milewski M, Szamburska O. Spectroscopic and HPLC studies of photodegradation of nilvadipine. Drug Dev Ind Pharm 2001;27:1031-8.

65. Ragno G, Veronico M, Vetuschi C. Analysis of nimodipine and its photodegradation product by derivative spectrophotometry and gas chromatography. Int J Pharm 1995;119:115-9.

66. Marinkovic V, Agbaba D, Karljikovic-Rajic K, Comor J, ZivanovStakic D. UV derivative spectrophotometric study of the photochemical degradation of nisoldipine. Il Farmaco 2000;55:128-33.

67. Marinkovic VD, Agbaba D, Karljikovic-Rajic K, Vladimirov S, Nedeljkovic JM. Photochemical degradation of solid-state nisoldipine monitored by HPLC. J Pharm Biomed Anal 2003;32:929-35.

68. Agbaba D, Vucicevic K, Marinkovic V. Determination of nisoldipine and its impurities in pharmaceuticals. Chromatographia 2004;60:223-7.

69. Tipre D, Vavia P. Oxidative degradation study of nitrendipine using stability indicating, HPLC, HPTLC and spectrophotometric method. J Pharm Biomed Anal 2001;24:705-14.

70. Alvarez-Lueje A, Sturm J, Squella JA, Nunez-Vergara LJ. Hydrolytic degradation of nitrendipine and nisoldipine. J Pharm Biomed Anal 2002;28:887-95.

71. Ragno G, Veronico M, Vetuschi C. Gas chromatographic and UV derivative determination of nitrendipine and its photodegradation product. Int J Pharm 1993;99:351-5.

72. Cortes M, Cardenas A, Hidalgo M, Glena C, Fernandez E, Sunkel C. New 4-alkyl-1,4-dihydropyridines: evaluation of photostability and phototoxic potential. J Photochem Photobiol B 1993; 19:135-8.

73. Baranda $\mathrm{AB}$, Alonso RM, Jimenez RM, Weinmann W. Instability of calcium channel antagonists during sample preparation for LC-MS-MS analysis of serum samples. Forensic Sci Int 2006;156:23-34. 
74. Gil-Agustí MT, Carda-Broch S, Ll Monferrer-Pons, EsteveRomero JS. Photostability studies for micellar liquid chromatographic determination of nifedipine in serum and urine samples. Biomed Chromatogr 2006;20:154-60.

75. Onoue S, Igarashi N, Yamauchi Y, Murase N, Zhou Y, Kojima T, et al. In vitro phototoxicity of dihydropyridine derivatives: a photochemical and photobiological study. Eur J Pharm Sci 2008;33:262-70.

76. De Luca M, Ioele G, Spatari C, Ragno G. Photostabilization studies of antihypertensive 1,4-dihydropyridines using polymeric containers. Int J Pharm 2016;505:376-82.

77. Mielcarek J, Grobelny P, Szamburska P. The effect of $\beta$-carotene on the photostability of nisoldipine. Methods Find Exp Clin Pharmacol 2005;27:167-71.

78. Sharma S, Saraogi GK, Kumar V. Development of spectrophotometric methods for simultaneous determination of artesunate and curcumin in liposomal formulation. Int J Appl Pharm 2015; 7:18-21.

79. Yunus YK, Vasanti S. Liposomes containing phytochemicals for cancer treatment-an update. Int J Curr Pharm Res 2017;9:20-4.

80. Ragno G, Risoli A, Loele G, Cione E, De Luca M. Photostabilization of 1,4-dihydropyridine antihypertensives by incorporation into $\beta$-cyclodextrin and liposomes. J Nanosci Nanotechnol 2006;6:9-10.

81. Mielcarek J. Studies on inclusion complexes of felodipine with $\beta$-cyclodextrin. J Inclusion Phenom Mol Recognit Chem 1998; 30:243-52.

82. Ragno G, Cione E, Garofalo A, Genchi G, Ioele G, Risoli A, et al. Design and monitoring of photostability systems for amlodipine dosage forms. Int J Pharm 2003;265:125-32.

83. Jang DJ, Jeong EJ, Lee HM, Kim BC, Lim SJ, Kim CK. Improvement of bioavailability and photostability of amlodipine using redispersible dry emulsion. Eur J Pharm Sci 2006;28:405-11.
84. Narkhede MR, Kuchekar BS, Nehete JY. Ternary systems of HP $\beta$-cyclodextrin felodipine inclusion complexes: preparation, characterization and solubility studies. Res J Pharm Technol 2011;4:1809-15.

85. Brito J, Pozo A, Garcia C, Nunez-Vergara L, Morales J, Gunther G, et al. Photodegradation of nimodipine and felodipine in microheterogeneous systems. J Chil Chem Soc 2012;57:1313-7.

86. Ioele G, De Luca M, Ragno G. Photostability of barnidipine in combined cyclodextrin-in-liposome matrices. Future Med Chem 2014;6:35-43.

87. Himabindu S, Sathish D, Kumar P, Shayeda S. Formulation and ex vivo evaluation of buccal tablets of isradipine in a $\beta$ cyclodextrin complex to improve the photostability. Curr Drug Ther 2013;8:121-31.

88. Park JBB, Lee GHH, Kang JWW, Jeon ISS, Kim JMM, Kim KBB, et al. Improvement of photostability and dissolution profile of isradipine using inclusion complex. J Pharm Investig 2013;43:55-61.

89. Pomponio R, Gotti R, Fiori J, Cavrini V, Mura P, Cirri M, et al. Photostability studies on nicardipine-cyclodextrin complexes by capillary electrophoresis. J Pharm Biomed Anal 2004;35:267-75.

90. Tagliari MP, Granada A, Segatto Silva MA, Stulzer HK, ZanettiRamos BG, Fernandes D, et al. Development of oral nifedipineloaded polymeric nanocapsules: physicochemical characterization, photostability studies, in vitro and in vivo evaluation. Quim Nova 2015;38:781-6.

91. Fujimoto $\mathrm{Y}$, Hirai $\mathrm{N}$, Takatani-Nakase $\mathrm{T}$, Takahashi $\mathrm{K}$. Photostable solid dispersion of nifedipine by porous calcium silicate. Chem Pharm Bull 2016;64:1218-21.

92. Shende MA, Markandeeywar T. Photostability studies and development of fast release nifedipine tablets. Int J Pharma Bio Sci 2010;1:1-14. 